\title{
Competitividade e Padrão de Especialização do Fluxo Industrial de Comércio Exterior do Paraná, 1996 a 2008
}

\author{
Lorena Vieira Costa ${ }^{1}$ \\ Marília Fernandes Maciel Gomes ${ }^{2}$ \\ Vladimir Faria dos Santos ${ }^{3}$ \\ Graciela Aparecida Profeta ${ }^{4}$
}

Resumo: Este trabalho tem o objetivo de analisar o comportamento e a estrutura do fluxo comercial externo de produtos industriais do Paraná, no período de 1996 a 2008. Para isso, utilizaram-se os Índices de Vantagem Comparativa Simétrica, de Contribuição ao Saldo, de Gini-Hischman e de Comércio Intraindústria. Os resultados revelaram que apenas dois setores da indústria paranaense obtiveram vantagem comparativa no período em análise: o das Indústrias alimentares, bebidas, fumos e seus sucedâneos e o que abrange Madeiras, carvão vegetal, cortiças e suas obras. Esses setores foram também os que mais contribuíram para o saldo comercial do estado. Os resultados dos índices de concentrações evidenciaram que o estado possui pauta exportadora industrial diversificada, mas exporta para poucos blocos econômicos. Já o índice de comércio intraindústria mostrou que o comércio internacional paranaense de bens industriais é basicamente interindustrial, ou seja, predomina o fluxo de bens entre diferentes setores de atividades.

Palavras-chave: Índices de Competitividade; Produtos manufaturados; Paraná.

JEL: F14.

\footnotetext{
1 Doutoranda em Economia pela Universidade Federal de Viçosa (UFV). E-mail: lorena.costa@ufu.br 2 Doutora em Economia Rural pela Universidade Federal de Viçosa (UFV). Professora assistente da UFV. E-mail: mfmgomes@ufv.br

3 Doutor em Economia pela Universidade Federal de Viçosa (UFV). Professor adjunto da UFF.

E-mail: vladi_fs@yahoo.com.br

4 Doutoranda em Economia Aplicada pela Universidade Federal de Viçosa (UFV).

E-mail: graciela_profeta@yahoo.com.br
} 


\title{
Competitiveness and the Standard Specialization of the Industrial Flow of Foreign Trade of Paraná, from 1996 to 2008
}

\begin{abstract}
This study aimed to analyze the behavior and structure of external trade flow of industrial products of Paraná, in the period 1996 to 2008. For this, we used the Indicator of Symmetric Comparative Advantage Index, Contribution to the Balance, the Gini-Hischman Index and Intra industrial Trade Index. The results revealed that only two sectors of the industry of the state had comparative advantage in the period: that was the section of Food, beverages, tobacco and its substitutes and the one that covers Wood, charcoal, cork and works. These were also the sectors that contributed most to the trade balance of the state. The results showed that the state has diversified industrial export list, but exports to few economic blocks. The index of intra industry trade showed that international trade in industrial goods of Parana is basically inter-industry, i.e., dominates the flow of goods between different industry sectors.
\end{abstract}

Key-words: Competitiveness Index; Manufactures; Paraná.

JEL: F14.

\section{Introdução}

O comércio mundial tem evoluído muito nos últimos anos. Entre 1996 e 2010, a corrente de comércio mundial ${ }^{1}$ aumentou de US $\$ 10,45$ trilhões para US\$30,21 trilhões, o que representou aumento de 288,94\% (IPEA, 2011). No caso do Brasil, as exportações que eram de US $\$ 47,7$ bilhões, cerca de 0,91\% do total exportado pelo mundo, em 1996, passaram a corresponder, em 2010, a US $\$ 201,9$ bilhões, representando 1,38\% das exportações mundiais, ou seja, um crescimento de $423,2 \%$ das exportações brasileiras no período.

Considerando a dimensão territorial do Brasil, bem como a heterogeneidade produtiva apresentada pelas diferentes regiões, é esperado que os efeitos do comércio internacional não se propaguem igualmente entre as mesmas. Segundo Feistel (2006), o desempenho das exportações e importações das regiões brasileiras não ocorreu de modo uniforme ao longo do tempo.

Em 2010, as regiões Sudeste e Sul foram responsáveis, respectivamente, por $57,2 \%$ e $18,3 \%$ do valor total exportado pelo país. Em se tratando da região Sul, coube ao Rio Grande do Sul uma participação de 41,4\% no valor das exportações dessa região e ao Paraná e Santa Catarina, 38,1\% e 20,4\%, respectivamente (SECEX, 2011). O Paraná, em face de seu potencial produtivo, além do dinamismo da indústria, foi o $5^{\circ}$ maior exportador nacional nesse ano. 
No que se refere à indústria na economia paranaense, segundo a Pesquisa Industrial Anual (IBGE, 2011), o crescimento da produção industrial desse estado em janeiro-agosto de 2011, frente a igual período de 2010 foi maior que a média nacional de $1,4 \%$. O estado obteve um crescimento de $4,8 \% \mathrm{em}$ sua produção industrial, fato decorrente do crescimento da produção de veículos automotores (25,2\%), refino de petróleo e produção de álcool (12,1\%) e máquinas, aparelhos e materiais elétricos (21,5\%).

A importância do setor industrial para o estado do Paraná ainda se faz notar na sua alta participação nas exportações totais. Em 1996, o setor industrial correspondia a, aproximadamente, $72 \%$ de toda a exportação; já em 2010, esse valor caiu para 59\%. Mesmo diante da queda, nota-se uma alta representatividade desse setor nas exportações totais do estado (SECEX, 2011). A pauta de exportações industriais do estado mostra a evolução da diversificação produtiva ocorrida. Em 1996, cerca de 43\% do valor total de produtos exportados (em US\$) referia-se a produtos das Indústrias de alimentos, bebidas, líquidos alcoólicos e vinagres, fumo e seus sucedâneos manufaturados. Já em 2010, este setor representava em torno de 21\%. Nesse mesmo ano, as exportações de Veículos automóveis, tratores, ciclos e outros veículos terrestres, suas partes e acessórios, totalizaram $13 \%$ do total exportado pelo estado (SECEX, 2011).

Em estudo realizado por Nojima (2002), foi observado que o Paraná apresentou tendência de crescimento da indústria ao mesmo tempo em que uma reestruturação produtiva da mesma. Além disso, o autor ressalta a existência de um movimento de mudança de indústrias tradicionais para tecnológicas.

Em face da importância do setor industrial para a economia do Paraná surge um importante questionamento: quais os produtos da indústria paranaense obtiveram vantagens comparativas no período de 1996 a 2008? Essa informação permite verificar quais contribuíram para a vantagem competitiva, relacionando, assim, os produtos de maior relevância para a pauta exportadora industrial paranaense, uma vez que a compreensão das vantagens comparativas permite uma análise em termos do aproveitamento de tais vantagens em benefício do País e, ou, da região em relação ao comércio internacional. A partir da análise das vantagens comparativas, pode-se ter uma melhor acepção das potencialidades comerciais da região e, neste caso, estabelecer políticas de comércio exterior, no sentido de se buscar que os acordos comerciais bilaterais ou com blocos econômicos de um país, contemplem as necessidades produtivas específicas do referido estado.

Além desta introdução, o trabalho está dividido em outras quatro seções. Na segunda são apresentados os aspectos teóricos; na terceira, a metodologia utilizada; na quarta, os resultados obtidos e, por fim, são apresentadas as conclusões do estudo. 


\section{Referencial Teórico}

O referencial teórico que sustenta o problema em análise baseia-se nas teorias do Comércio Internacional, especificamente, na Teoria das Vantagens Comparativas e Teoria da Dotação Relativa de Fatores de Eli Heckscher e Bertil Ohlin. A teoria de Heckscher-Ohlin, (HO) procura explicar a fonte das diferenças entre as produtividades entre os Países. Também sustentada no objetivo de explicar os diferentes custos, a teoria considera os custos em termos das diferentes dotações de fatores entre os Países. Na forma mais simplificada da teoria, admite-se que os fatores sejam divididos em duas classes: capital e trabalho. A tecnologia é considerada idêntica entre os países. Em geral, uma nação tenderá a ser relativamente eficaz na produção de bens que sejam intensivos nos fatores dos quais o mesmo é bem dotado. Dessa forma, um país, por meio do comércio internacional, exporta bens em que possui eficácia na produção e importa bens cuja produção necessita de fatores localmente escassos. Um país pode, assim, se especializar em um conjunto restrito de bens, dando a ele maior eficiência na produção em larga escala (Krugman e Obstfeld, 2005).

O comércio do tipo HO, é o comércio interindústria, que consiste na importação e exportação de bens de setores diferentes, refletindo as vantagens comparativas em relação à dotação de fatores de produção entre as regiões. De modo paralelo, quando há a troca de produtos de um mesmo setor industrial entre Países, tem-se o comércio intraindústria (Feistel, 2006).

O termo comércio intraindústria foi descrito, inicialmente por Grubel e Lloyd (1975). Segundo eles o comércio intraindústria deve ser entendido como: "O valor das exportações de uma indústria que é exatamente compensado por importações da mesma indústria.” Segundo Hidalgo e da Mata (2003), o comércio com base nas vantagens comparativas pela disponibilidade de dotação de fatores tende a diminuir na medida em que há o aumento das semelhanças tecnológicas entre os Países, ocasionando um aumento natural do comércio intraindústria. Assim, esta corrente teórica discute as implicações das economias de escala e da concorrência monopolística dentro do comércio internacional. De acordo Feistel (2006), nessa percepção, o comércio pode ser explicado mesmo quando o fluxo de bens apresenta intensidade de fatores semelhantes.

Desse modo, a existência do comércio é justificada por vantagens em economias de escala, e não pelas diferenças entre as dotações de recursos. Um país, ao adquirir custos decrescentes à escala na produção de um bem, especializa-se neste e garante sua competitividade no comércio internacional. Desta forma, a explicação do fluxo de comércio intraindústria, segundo Krugman (1981), está entrelaçada à economia de escala, e à consideração de que a indústria não é perfeitamente competitiva, sendo ela capaz de produzir produtos diferenciados. As economias de escala evitam que um país produza toda a variedade de produtos por si mesmo. 
Diante do exposto, nota-se que a vantagem comparativa tem papel fundamental no comércio interindústria, enquanto que as economias de escala, por si só, estimulam o comércio internacional, caracterizando o comércio do tipo intraindústria (Guimarães, 2007).

\section{Metodologia}

Os índices de competitividade utilizados foram: Índice de Vantagem Comparativa Simétrica; Índice de Contribuição ao Saldo Comercial; Índice Gini-Hischman (Índice de Concentração das Exportações); e o Índice de Comércio Intraindústria.

\section{1 Índice de Vantagens Comparativas Simétricas}

O índice de vantagem comparativa simétrica é construído a partir do índice de vantagem comparativa revelada (VCR). O VCR é utilizado para determinar os setores sobre os quais uma região possui vantagem comparativa e revela a evolução do poder de competitividade de cada setor, fundamentado em dados observados após a realização do comércio (Balassa, 1965). Matematicamente, o VCR é dado por:

$$
V C R_{i j}=\frac{\left(X_{i j} / X_{i z}\right)}{\left(X_{j} / X_{z}\right)}
$$

em que $j$ representa o Paraná e $z$ é a zona de referência, no caso o Brasil. Logo, $X_{i j}$ é o valor das exportações do produto $i$ pelo Paraná, e $X_{i z}$ é o valor das exportações brasileiras do produto $i$. $X_{j}$ é o valor total das exportações do estado e, por fim, $X_{z}$ é o valor total das exportações do país.

O estado apresentará vantagem comparativa revelada na exportação do produto $i$ se o valor do índice superar a unidade, e terá desvantagem comparativa revelada se o valor do índice for menor que a unidade.

Alguns aspectos técnicos devem ser mencionados a respeito desse índice. O VCR desconsidera as importações e obtém resultados que são assimétricos. Assim, a vantagem comparativa assume valores que variam entre $1 \mathrm{e}$ infinito, enquanto que a desvantagem comparativa varia apenas em o e 1. Na tentativa de suavizar a assimetria presente nesse índice, tem-se o índice de vantagem comparativa revelada simétrica VCS (Laursen, 1998 apud Holland e Xavier, 2005):

$$
V C S_{i j}=\frac{V C R_{i j}-1}{V C R_{i j}+1}
$$


Esse índice obtém valores que variam entre -1 e 1, com um valor médio centrado em zero, tornando simétrico o índice VCR. A região possuirá vantagem comparativa revelada no produto $i$ se o valor do VCS se encontrar entre o e 1. De modo análogo, valores entre -1 e o, indicam que a região possui desvantagem comparativa revelada no produto $i$.

\section{2 Índice de Contribuição ao Saldo Comercial}

O Índice de Contribuição ao Saldo (CS) consiste na comparação do saldo comercial de cada produto, ou grupo de produtos, com o saldo comercial teórico desse mesmo produto (Rocha e Leite, 2007). O saldo teórico constitui no saldo global de um país distribuído de maneira equiproporcional entre os diversos setores presentes na balança comercial deste país (Xavier, 2001). A justificativa para o uso de tal indicador é a de que, não só as importações estão sujeitas a vieses associados às distorções do mercado internacional, mas também as exportações são condicionadas por subsídios fiscais ou financeiros. Assim, a versão final do indicador Índice de Contribuição ao Saldo (CS) é a seguinte:

$$
C S=\frac{100}{\frac{(X+M)}{2}}\left[\left(X_{i}-M_{i}\right)-(X-M)\left(\frac{X_{i}+M_{i}}{X+M}\right)\right]
$$

representa as exportações do setor $i$ efetuadas pelo estado; e $M i$ se refere às importações deste mesmo setor; já $X$ e $M$, são respectivamente as exportações e importações totais do estado do Paraná.

Valores positivos para o índice CS indicam que a região apresenta vantagem comparativa no setor em questão. Por outro lado, valores negativos mostram desvantagem comparativa do mesmo. Nesse sentido, espera-se que os produtos mais exportados pela região sejam os produtos que mais contribuem para o saldo comercial, e que sejam também os produtos com maiores vantagens comparativas.

\section{3 $O$ coeficiente de concentração das exportações: o índice de Gini-Hischman}

O coeficiente de Gini-Hirchman é utilizado com a finalidade de mensurar a concentração das exportações em termos de produtos e mercados de destino. De acordo com Love (1979) apud Silva e Montalván (2008), o índice de GiniHischman para o cálculo da concentração de produtos, (ICP), é apresentado da seguinte maneira: 


$$
I C P=\sqrt{\sum\left[\frac{X_{i j}}{X_{j}}\right]^{2}}
$$

em que $X_{i j}$ se refere às exportações do bem $i$ pelo país $j$, e $X_{j}$ representa as exportações totais do país $j$. Neste caso, serão utilizados os dados referentes às exportações do Paraná.

O valor desse índice está contido no intervalo [0,1]. Valores próximos de zero indicam que a região possui maior diversificação da pauta exportadora. Nesse caso, a região terá maior estabilidade nas receitas advindas do comércio internacional. De acordo com Hidalgo e Mata (2003), o nível de desenvolvimento econômico, a proximidade a pólos comerciais e o tamanho da economia, são alguns dos fatores que determinam o grau de diversificação das exportações. Já valores de ICP próximos de 1, correspondem a um forte grau de concentração de produtos exportados, indicando que o comércio está concentrado em poucos produtos, ou setores, evidenciando o alto grau de especialização dessa economia.

Para a mensuração do grau de concentração das exportações entre os países importadores, calcula-se o índice de concentração por países de destino (ICD), da seguinte forma, segundo Love (1979) apud Silva e Montalván (2008) :

$$
I C D=\sqrt{\sum\left[\frac{X_{i j}}{X_{j}}\right]^{2}}
$$

em que $\mathrm{X}_{i j}$ representa as exportações do país $j$ para o país $i$, e $\mathrm{X}_{j}$ indica as exportações totais do país j. Novamente, para o caso do Paraná, são utilizados dados referentes às exportações totais do estado.

Da mesma forma que o ICP, este índice varia entre o e 1; em que valores altos implicam que há alta concentração das exportações por países de destino. Nesse caso, um pequeno número de países importa grande parcela da exportação do estado. Por outro lado, valores baixos refletem uma participação mais equilibrada nos diversos mercados, permitindo ao estado menores flutuações na receita cambial.

\section{4 Índice de comércio intraindústria}

Com o intuito de classificar o comércio exterior de uma economia em interindustrial ou intraindustrial, foi proposto por Grubel e Lloyd (1975) o índice de comércio intraindústria (GL). O índice em nível de cada indústria é representado da seguinte maneira: 


$$
G L_{i}=\frac{\left(X_{i}+M_{i}\right)-\left|X_{i}-M_{i}\right|}{\left(X_{i}+M_{i}\right)}
$$

em que $X_{i}$ e $M_{i}$ representam, respectivamente, o valor exportações e importações da indústria $i$. Sendo que $(X i+M i)$ representa o comércio total da indústria $i ;(X i+M i)$ - $|X i-M i|$ o comércio intraindústria, e, por conseguinte, $X i-M i$, o comércio interindústria.

O valor do índice GL varia entre o e 1. Quando o índice é igual a zero, todo o comércio é explicado pelo comércio interindústria, aquele que segue os moldes do teorema de Heckscher-Ohlin, sendo, neste caso, ou as importações ou as exportações de cada bem $i$ iguais a zero. Por outro lado, valores iguais a um, indicam que todo o comércio é intraindústria. Nesse caso o valor das exportações é igual ao valor das importações do bem $i$. Para valores maiores que zero, porém menores que a unidade, pode-se dizer que as dotações de fatores são diferentes entre as regiões, ou países, e existem efeitos da economia de escala e diferenciação de produtos. Considera-se que para $\mathrm{GL} i>0,5$, o comércio é intraindustrial. Logo, os efeitos das economias de escala e da diferenciação de produtos compensam os efeitos relacionados com as diferenças nas dotações relativa dos fatores. Já no caso de GLi $<0,5$, tem-se o comércio interindústria, e nesse caso, os efeitos relacionados com as diferenças nas dotações dos fatores compensam os efeitos da economia de escala e da diferenciação de produtos (Guimarães, 2007).

Analogamente, o índice agregado de comércio intraindústria, para toda a economia, pode ser representado da seguinte forma:

$$
C I I A=1-\frac{\sum\left|X_{i}-M_{i}\right|}{\sum\left(X_{i}+M_{i}\right)}
$$

em que $X i$ e $M i$ representam, respectivamente, as exportações e importações do produto $i$ pelo Paraná. O valor numérico deste índice está no intervalo entre o e 1. Sendo que, todo o comércio será do tipo interindústria se o valor do índice for igual a 0 . Em sentido oposto, se o valor do índice for igual à unidade, todo o comércio é explicado pelo comércio intra-indústria. 


\subsection{Fonte dos dados e definição das variáveis}

O período de análise foi de 1996 a 2008. Utilizaram-se dados disponíveis no sistema Alice Web, do Ministério do Desenvolvimento da Indústria e do Comércio (MDIC), utilizando a Nomenclatura Comum do Mercosul (NCM)². Foram considerados produtos industrializados aqueles que pertencem da seção IV à XVII e seção XX, exceto as seções XIII e XIV. As seções foram escolhidas de forma a contemplar toda a indústria paranaense. Mais especificamente, as seções utilizadas foram as seguintes: Seção IV: Produtos das indústrias alimentares, bebidas, líquidos alcoólicos e vinagres, fumo (tabaco) e seus sucedâneos manufaturados. Seção V: Produtos minerais. Seção VI: Produtos das indústrias químicas ou conexas. Seção VII: Plásticos, borracha e suas obras. Seção VIII: Peles, couros, peleteria e obras destas matérias, artigos de correeiro ou de seleiro, artigos de viagem, bolsas e artefatos semelhantes, obras de tripa. Seção IX: Madeira, carvão vegetal e obras de madeira; cortiça e suas obras, obras de espataria, ou de cestaria. Seção X: Pastas de madeira ou de matérias fibrosas celulósicas, papel ou cartão de reciclar; papel e suas obras. Seção XI: Matérias têxteis e suas obras. Seção XII: Calçados, chapéus e artefatos de uso semelhante, guarda-chuvas, guarda-sóis, bengalas, chicotes, e suas partes, penas preparadas e suas obras, flores artificiais, obras de cabelo. Seção XV: Metais comuns e suas obras. Seção XVI: Máquinas e aparelhos, material elétrico, e suas partes; aparelhos de gravação ou de reprodução de som, aparelhos de gravação ou de reprodução de imagens e de som em televisão, e suas partes e acessórios. Seção XVII: Material de transporte. Seção XX: Mercadorias e Produtos diversos.

\section{Resultados e Discussão}

Os resultados obtidos por meio do cálculo do índice de Vantagem Comparativa Revelada Simétrica (VCS) para o setor industrial paranaense mostrou que, durante o período analisado, dois setores obtiveram vantagem comparativa (valores positivos): o grupo de produtos das Indústrias alimentares, bebidas, líquidos alcoólicos e vinagres; fumo e seus sucedâneos manufaturados (Seção IV) e o grupo que compreende Madeiras, carvão vegetal e obras de madeira; cortiça e suas obras; obras de espataria ou de cestaria (Seção IX) (Tabela 1).

2 A NCM compreende 21 seções, compostas por 96 capítulos. Os capítulos, por sua vez são divididos em posições e subposições, atribuindo-se códigos numéricos a cada um dos desdobramentos. 
TABELA 1. ÍNDICE DE VANTAGEM COMPARATIVA REVELADA SIMÉTRICA DO PARANÁ, 1996-2002

\begin{tabular}{lccccccr}
\hline Seçõaes da NCM & 1996 & 1997 & 1998 & \multicolumn{1}{c}{1999} & \multicolumn{1}{c}{2000} & \multicolumn{1}{c}{2001} & \multicolumn{1}{c}{2002} \\
\hline Seção IV & 0,398 & 0,389 & 0,340 & 0,281 & 0,309 & 0,215 & 0,172 \\
Seção V & $-0,741$ & $-0,767$ & $-0,960$ & $-0,919$ & $-0,921$ & $-0,912$ & $-0,850$ \\
Seção VI & $-0,551$ & $-0,589$ & $-0,549$ & $-0,454$ & $-0,425$ & $-0,449$ & $-0,496$ \\
Seção VII & $-0,888$ & $-0,884$ & $-0,833$ & $-0,824$ & $-0,806$ & $-0,795$ & $-0,735$ \\
Seção VIII & 0,167 & 0,096 & 0,118 & 0,129 & 0,097 & $-0,056$ & $-0,100$ \\
Seção IX & 0,456 & 0,470 & 0,538 & 0,604 & 0,603 & 0,567 & 0,565 \\
Seção X & 0,018 & $-0,107$ & $-0,095$ & $-0,116$ & $-0,162$ & $-0,181$ & $-0,195$ \\
Seção XI & $-0,196$ & $-0,237$ & $-0,181$ & $-0,289$ & $-0,336$ & $-0,391$ & $-0,440$ \\
Seção XII & $-0,941$ & $-0,939$ & $-0,865$ & $-0,837$ & $-0,867$ & $-0,903$ & $-0,861$ \\
Seção XV & $-0,910$ & $-0,872$ & $-0,863$ & $-0,836$ & $-0,802$ & $-0,779$ & $-0,783$ \\
Seção XVI & $-0,179$ & $-0,205$ & $-0,169$ & $-0,193$ & $-0,269$ & $-0,239$ & $-0,148$ \\
Seção XVII & $-0,548$ & $-0,482$ & $-0,569$ & $-0,482$ & 0,091 & 0,117 & 0,126 \\
Seção XX & $-0,040$ & $-0,081$ & $-0,114$ & $-0,014$ & 0,066 & $-0,037$ & $-0,087$ \\
\hline
\end{tabular}

FONTE: Resultados da pesquisa.

TABELA 1 (continuação). ÍNDICE DE VANTAGEM COMPARATIVA REVELADA SIMÉTRICA DO PARANÁ, 2003-2008

\begin{tabular}{lrrrrrr}
\hline Seções da NCM & 2003 & 2004 & 2005 & 2006 & 2007 & 2008 \\
\hline Seção IV & 0,175 & 0,163 & 0,139 & 0,199 & 0,216 & 0,272 \\
Seção V & $-0,972$ & $-0,962$ & $-0,936$ & $-0,861$ & $-0,831$ & $-0,889$ \\
Seção VI & $-0,417$ & $-0,441$ & $-0,407$ & $-0,341$ & $-0,333$ & $-0,273$ \\
Seção VII & $-0,719$ & $-0,695$ & $-0,646$ & $-0,597$ & $-0,604$ & $-0,618$ \\
Seção VIII & $-0,311$ & $-0,400$ & $-0,238$ & $-0,172$ & $-0,130$ & $-0,187$ \\
Seção IX & 0,576 & 0,595 & 0,622 & 0,643 & 0,603 & 0,606 \\
Seção X & $-0,221$ & $-0,144$ & $-0,073$ & 0,003 & $-0,030$ & $-0,002$ \\
Seção XI & $-0,421$ & $-0,385$ & $-0,325$ & $-0,084$ & $-0,182$ & $-0,090$ \\
Seção XII & $-0,879$ & $-0,901$ & $-0,911$ & $-0,895$ & $-0,839$ & $-0,856$ \\
Seção XV & $-0,732$ & $-0,707$ & $-0,616$ & $-0,637$ & $-0,651$ & $-0,708$ \\
Seção XVI & $-0,060$ & 0,059 & 0,002 & 0,054 & 0,006 & $-0,044$ \\
Seção XVII & 0,078 & $-0,105$ & 0,200 & 0,116 & 0,119 & 0,107 \\
Seção XX & $-0,049$ & $-0,023$ & 0,017 & 0,176 & 0,132 & 0,212 \\
\hline
\end{tabular}

FONTE: Resultados da pesquisa.

Segundo a Federação das Indústrias do Estado do Paraná - FIEP (2005), a indústria alimentícia está entre aquelas tidas como estratégicas para o estado, e, portanto, merece especial atenção, no sentido de se fomentar a sua impulsão. O desenvolvimento dessa indústria passa por ações de caráter estadual, tais como o apoio à diversificação mediante o desenvolvimento de novas tecnologias de processos produtivos, com vistas a elevar a competitividade do setor. 
É importante observar que o grupo das Indústrias alimentares (Seção IV), embora apresente VCS em todo o período, mostrou uma tendência decrescente dos valores. Segundo Trintin (2005), entre os anos de 1975 e 1998, setores tradicionais da indústria paranaense, como os Produtos alimentares, Têxtil e Madeira, perderam participação no valor adicionado da indústria, enquanto que setores como o de Material de transporte, Indústria química e Material elétrico e de comunicação ampliaram sua participação. Segundo dados do MDIC (2009), a participação da exportação paranaense do grupo dos Produtos alimentares no total exportado pelo Brasil decresceu, passando de 20,63\% em 1996, para 13,43\% em 2008.

O grupo das Madeiras, cortiças e suas obras (Seção IX) também apresentou VCS em todo o período analisado. Conforme Trintin (2005), essa seção também reduziu sua participação no valor adicionado da indústria de transformação do Paraná, entre 1975 e 1998, porém as transformações dentro deste grupo mostram que houve o avanço de segmentos com maior complexidade tecnológica, como a fabricação de laminados e de MDF. Em 1996 as exportações paranaenses desse grupo correspondiam a 23,77\% do total exportado pelo país. Já em 2008, esse valor foi de 31,37\% (MDIC, 2009).

Destaca-se que outros setores obtiveram vantagem comparativa em alguns períodos, como a seção VIII - Peles, couros, peleteria e obras, que apresentou valores positivos do ano de 1996 a 2000. Maia e Trintin (2003) constatam que esse grupo obteve vantagem comparativa revelada no período de 1989 a 2000. Embora esses autores utilizem o índice de Vantagem Comparativa Revelada e não o VCS, o resultado é coerente com o encontrado neste estudo. A participação desse grupo na exportação nacional em 1996 era de 12,45\% e, em 2008, caiu para 5,26\% (MDIC, 2009).

Para o grupo dos Materiais de transporte (Seção XVII), o índice mostrou vantagem comparativa a partir do ano 2000, com exceção no ano de 2004. Conforme Sesso Filho et. al. (2004), a consolidação da indústria automobilística no Paraná ocorreu na década de 1990 com a abertura comercial da economia brasileira, embora a indústria tenha iniciado suas atividades ainda na década de 70. O setor contou com incentivos fiscais, financeiros e de infra-estrutura do estado para a instalação de empresas na região de Curitiba. Dessa forma, justifica-se o aumento extraordinário das exportações do grupo de materiais de transporte, que passou de US\$ 96 milhões em 1996 para US\$ 2,1 bilhões em 2008. A participação paranaense na exportação brasileira desse grupo em 1996 era de 2,59\% e, em 2008, 9,54\% (MDIC, 2009).

A seção XX - Mercadorias e produtos diversos que contempla móveis, mobiliário médico-cirúrgico, construções pré-fabricadas, e outros, obteve VCS, no ano 2000, e a partir de 2005. O estado exportou em 1996 o equivalente a $8,21 \%$ do total nacional e, em 2008, 11,84\% (MDIC, 2009). De acordo com a FIEP (2005) a indústria moveleira é uma das maiores empregadoras do 
estado, porém necessita de uma mudança quanto aos processos de produção, no sentido de modernizar-se, e tornar-se mais competitiva.

Os produtos pertencentes ao grupo de Máquinas e aparelhos, materiais elétricos e de comunicação (Seção XVI) obtiveram VCS entre os anos de 2004 e 2007. Em 1996, o Paraná foi responsável por 6,19\% do total exportado pelo país e em 2008, esse valor subiu para 7,04\% (MDIC, 2009).

Por fim, o grupo das Pastas de madeira ou de matérias fibrosas celulósicas, papel ou cartão de reciclar (Seção X), mostrou VCS em apenas dois anos: 1996 e 2006. Observa-se que o Paraná perdeu participação no total de exportações brasileiras desse grupo, passando de 9,21\% em 1996, para 7,66\%, em 2008 (MDIC, 2009). O estado, segundo a FIEP (2005) necessita desenvolver uma indústria de papel mais moderna, tecnificada e limpa, para que se torne mais competitivo.

As demais seções estudadas, pertencentes à indústria paranaense, não apresentaram vantagem comparativa revelada simétrica no período analisado.

A incorporação das importações, por meio do cálculo do índice de Contribuição ao Saldo Comercial (CS) possibilitou que outras seções, que não apresentaram vantagens comparativas por meio do índice de VCS, se mostrassem competitivas, e essas foram: Peles, couros e peleteria (Seção VIII) e Materiais e produtos diversos (Seção XX). Os valores encontrados podem ser visualizados na Tabela 2.

Embora os índices VCS e CS não sejam diretamente comparáveis, nota-se que de modo análogo ao resultado obtido com o primeiro, a seção com maior contribuição ao saldo foi a das Indústrias alimentares, bebidas e fumos. Os resultados obtidos para este setor e para a seção que compreende Madeiras, carvão vegetal, cortiças e suas obras permitem afirmar que os produtos com vantagens comparativas foram também produtos com capacidade de gerar saldos comerciais positivos. De acordo com esta proposição, o estado possui saldo comercial positivo para os produtos intensivos em fatores de produção localmente abundantes; fato que o leva a especialização na produção dos mesmos. 
TABELA 2. ÍNDICE DE CONTRIBUIÇÃO AO SALDO PARA A INDÚSTRIA DO PARANÁ, 1996-2002

\begin{tabular}{lrrrrrrr}
\hline Seções da NCM & 1996 & 1997 & 1998 & 1999 & 2000 & 2001 & 2002 \\
\hline Seção IV & 36,40 & 32,73 & 28,86 & 25,31 & 19,39 & 19,68 & 15,99 \\
Seção V & $-13,10$ & $-11,92$ & $-7,03$ & $-9,58$ & $-16,42$ & $-12,66$ & $-9,02$ \\
Seção VI & $-11,63$ & $-10,34$ & $-8,79$ & $-9,37$ & $-10,93$ & $-9,63$ & $-13,76$ \\
Seção VII & $-4,46$ & $-3,13$ & $-3,86$ & $-6,26$ & $-6,87$ & $-6,56$ & $-5,66$ \\
Seção VIII & 1,79 & 1,60 & 1,75 & 1,69 & 1,54 & 1,29 & 1,05 \\
Seção IX & 4,34 & 4,96 & 6,46 & 11,26 & 9,62 & 8,91 & 9,49 \\
Seção X & $-0,41$ & $-0,28$ & 0,48 & 1,03 & 0,06 & 0,66 & 0,15 \\
Seção XI & $-3,38$ & $-2,12$ & $-0,46$ & $-0,39$ & $-0,56$ & $-0,68$ & $-1,98$ \\
Seção XII & $-0,03$ & $-0,01$ & 0,12 & 0,19 & 0,14 & 0,11 & 0,12 \\
Seção XV & $-1,48$ & $-1,34$ & $-1,71$ & $-2,20$ & $-3,56$ & $-2,30$ & $-2,18$ \\
Seção XVI & $-13,62$ & $-18,68$ & $-16,41$ & $-20,32$ & $-20,12$ & $-26,51$ & $-16,65$ \\
Seção XVII & $-1,50$ & $-8,59$ & $-24,06$ & $-16,59$ & $-2,74$ & 1,81 & 0,89 \\
Seção XX & 0,44 & 0,36 & 0,28 & 0,35 & 0,37 & 0,21 & 0,12 \\
\hline
\end{tabular}

FONTE: Resultados da pesquisa.

TABELA 2 (continuação). ÍNDICE DE CONTRIBUIÇÃO AO SALDO PARA A INDÚSTRIA DO PARANÁ, 2003-2008

\begin{tabular}{lrrrrrr}
\hline Seções da NCM & 2003 & 2004 & 2005 & 2006 & 2007 & \multicolumn{1}{c}{2008} \\
\hline Seção IV & 13,98 & 11,94 & 10,84 & 15,27 & 15,45 & 10,81 \\
Seção V & $-10,01$ & $-9,10$ & $-11,15$ & $-20,88$ & $-17,92$ & $-20,16$ \\
Seção VI & $-14,20$ & $-17,92$ & $-13,09$ & $-12,96$ & $-14,85$ & $-18,55$ \\
Seção VII & $-3,88$ & $-3,79$ & $-4,50$ & $-3,76$ & $-3,62$ & $-3,31$ \\
Seção VIII & 0,59 & 0,36 & 0,60 & 0,88 & 1,02 & 0,38 \\
Seção IX & 8,81 & 9,74 & 8,86 & 9,25 & 7,78 & 3,16 \\
Seção X & 0,44 & 0,00 & 0,20 & 0,91 & 1,27 & 0,72 \\
Seção XI & $-0,88$ & $-0,70$ & $-0,06$ & 0,21 & 0,01 & 0,00 \\
Seção XII & 0,09 & 0,04 & 0,02 & 0,02 & 0,05 & $-0,06$ \\
Seção XV & $-1,64$ & $-1,94$ & $-1,55$ & $-2,00$ & $-2,15$ & $-2,50$ \\
Seção XVI & $-14,95$ & $-13,28$ & $-15,56$ & $-9,24$ & $-12,40$ & $-13,39$ \\
Seção XVII & 0,04 & $-0,36$ & 6,51 & 1,20 & $-1,26$ & $-4,30$ \\
Seção XX & 0,15 & 0,20 & 0,25 & 0,53 & 0,43 & 0,18 \\
\hline
\end{tabular}

FONTE: Resultados da pesquisa.

Denota-se que as seções com valores negativos para todo o período são as mesmas em que o estado obteve desvantagem comparativa revelada simétrica. Os produtos da Indústria química e conexa e Máquinas, aparelhos e materiais elétricos foram os que mostraram maior desvantagem comparativa de acordo com o índice (Seções VI e XVI). Tal fato revela um saldo comercial desfavorável para produtos relativamente intensivos em ciência e tecnologia. Segundo a FIEP (2005), em 2003, os profissionais de ciência e tecnologia representaram nas indústrias do estado pequena parcela do emprego total (3,6\% em média). 
A seguir apresentam-se os resultados obtidos por meio da aplicação do índice Gini-Hirschman, especificamente para o cálculo do grau de concentração por produtos (ICP). Os resultados obtidos variaram entre 0,26 e 0,44 , com uma média ao longo do período analisado de 0,30 (30\%). Esse valor implica que as exportações do setor industrial paranaense foram, durante o período de análise, relativamente diversificadas. A variação anual do índice mostra que, em geral, houve variação negativa do mesmo, evidenciando a diminuição da concentração da pauta exportadora industrial do estado. Em 1996 o índice era de $44 \%$, caindo para $26 \%$, em 2008 , representando uma queda de, aproximadamente, 40\% no nível de concentração, a uma taxa média anual de redução de 4,03\% (Tabela 3). Essa queda denota uma maior diversificação da pauta exportadora do estado, fato que o torna relativamente mais independente em relação às possíveis mudanças no cenário internacional.

TABELA 3. ÍNDICE DE CONCENTRAÇÃO DAS EXPORTAÇÕES POR PRODUTOS, 1996-2008

\begin{tabular}{cccc}
\hline Anos & ICP & Evolução (1996 = 100\%) & Variação Anual (\%) \\
\hline 1996 & 0,446 & 100 & \\
1997 & 0,386 & 86,37 & $-13,62$ \\
1998 & 0,335 & 75,08 & $-13,07$ \\
1999 & 0,304 & 68,04 & $-9,37$ \\
2000 & 0,310 & 69,42 & 2,02 \\
2001 & 0,296 & 66,44 & $-4,28$ \\
2002 & 0,280 & 62,78 & $-5,52$ \\
2003 & 0,265 & 59,49 & $-5,24$ \\
2004 & 0,265 & 59,38 & $-0,18$ \\
2005 & 0,298 & 66,77 & 12,45 \\
2006 & 0,294 & 65,94 & $-1,25$ \\
2007 & 0,273 & 61,28 & $-7,07$ \\
2008 & 0,264 & 59,27 & $-3,28$ \\
\hline Média & 0,309 & & $-4,03$ \\
\hline
\end{tabular}

FONTE: Resultados da pesquisa.

Conforme Cunha Filho e Carvalho (2005), regiões tidas como diversificadas em relação às suas exportações, têm um maior nível de desenvolvimento econômico, partindo do pressuposto de que quanto maior o nível de desenvolvimento, mais complexa a estrutura produtiva e, consequentemente, maior grau de diversificação de sua pauta exportadora. Excluem-se dessa hipótese a possibilidade da especialização da economia na produção de bens intensivos nos fatores de produção localmente abundantes. Segundo os mesmos autores, o tamanho da economia também interfere nos valores do índice. Uma economia pequena tende a apresentar altos valores de ICP, pois esta economia teria menores possibilidades de produzir em larga escala uma ampla diversidade de bens. 
Os resultados da mensuração do grau de concentração das exportações por Blocos de destino (ICD) por meio do Índice de Gini-Hirschman estão expostos na Tabela 4. Entre os anos de 1996 e 2008, o índice apresentou valores que variaram entre 0,43 e o,55. Em média, houve uma concentração de $47 \%$ em relação aos destinos de exportações, com uma taxa média anual de redução de 1,85\% no grau de concentração. Os resultados assinalam uma relativa concentração das exportações do setor industrial paranaense em relação aos blocos econômicos de destino.

Apesar da tendência decrescente observada, os valores encontrados são considerados altos, fato que torna as exportações industriais do estado mais vulneráveis em relação a possíveis choques de demanda, provocadas por deteriorações macroeconômicas.

TABELA 4. ÍNDICE DE CONCENTRAÇÃO DAS EXPORTAÇÕES POR BLOCOS DE DESTINO, 1996-2008

\begin{tabular}{cccc}
\hline Anos & ICD & Evolução (1996 = 100\%) & Variação Anual (\%) \\
\hline 1996 & 0,556 & 100 & \\
1997 & 0,485 & 87,30 & $-12,70$ \\
1998 & 0,465 & 83,59 & $-4,25$ \\
1999 & 0,470 & 84,44 & 1,02 \\
2000 & 0,465 & 83,70 & $-0,88$ \\
2001 & 0,500 & 89,85 & 7,35 \\
2002 & 0,507 & 91,19 & 1,48 \\
2003 & 0,474 & 85,30 & $-6,46$ \\
2004 & 0,476 & 85,65 & 0,41 \\
2005 & 0,468 & 84,16 & $-1,74$ \\
2006 & 0,439 & 79,04 & $-6,09$ \\
2007 & 0,441 & 79,36 & 0,41 \\
2008 & 0,438 & 78,73 & $-0,79$ \\
\hline Média & 0,476 & & $-1,85$ \\
\hline
\end{tabular}

FONTE: Resultados da pesquisa.

É possível verificar, por meio da Tabela 5, os resultados do cálculo do ICD para cada Bloco Econômico de destino. Durante os anos em estudo, em média, a União Européia foi o destino de $35 \%$ das vendas de produtos industriais ao exterior, seguida pelo NAFTA e Mercosul, que detiveram 20\% e 15\% das exportações da indústria paranaense, respectivamente. 
TABELA 5. ÍNDICE DE CONCENTRAÇÃO DAS EXPORTAÇÕES INDUSTRIAIS POR BLOCOS ECONÔMICOS DE DESTINO, 1996-2002

\begin{tabular}{lccccccc}
\hline Blocos Econômicos & 1996 & 1997 & 1998 & 1999 & 2000 & 2001 & 2002 \\
\hline União Européia & 0,512 & 0,429 & 0,401 & 0,389 & 0,322 & 0,349 & 0,343 \\
Ásia (exclusive Oriente Médio) & 0,125 & 0,125 & 0,100 & 0,110 & 0,086 & 0,065 & 0,087 \\
Nafta & 0,111 & 0,104 & 0,104 & 0,164 & 0,244 & 0,311 & 0,338 \\
Mercosul & 0,122 & 0,140 & 0,167 & 0,154 & 0,186 & 0,137 & 0,065 \\
Aladi (exclusive Mercosul) & 0,033 & 0,055 & 0,054 & 0,053 & 0,096 & 0,077 & 0,096 \\
Liga Árabe & 0,023 & 0,023 & 0,028 & 0,029 & 0,020 & 0,023 & 0,032 \\
Tigres Asiáticos & 0,039 & 0,031 & 0,022 & 0,036 & 0,022 & 0,025 & 0,034 \\
África (exclusive Oriente Médio) & 0,029 & 0,033 & 0,044 & 0,036 & 0,024 & 0,026 & 0,034 \\
Caricom & 0,001 & 0,000 & 0,000 & 0,001 & 0,004 & 0,003 & 0,005 \\
\hline
\end{tabular}

FONTE: Resultados da pesquisa.

TABELA 5 (continuação). ÍNDICE DE CONCENTRAÇÃO DAS EXPORTAÇÕES INDUSTRIAIS POR BLOCOS ECONÔMICOS DE DESTINO, 2003-2008

\begin{tabular}{lcccccc}
\hline Blocos Econômicos & 2003 & 2004 & 2005 & 2006 & 2007 & 2008 \\
\hline União Européia & 0,320 & 0,332 & 0,336 & 0,296 & 0,306 & 0,312 \\
Ásia (exclusive Oriente Médio) & 0,115 & 0,076 & 0,074 & 0,084 & 0,070 & 0,078 \\
Nafta & 0,295 & 0,227 & 0,243 & 0,217 & 0,178 & 0,112 \\
Mercosul & 0,107 & 0,136 & 0,131 & 0,171 & 0,197 & 0,238 \\
Aladi (exclusive Mercosul) & 0,084 & 0,115 & 0,148 & 0,136 & 0,152 & 0,122 \\
Liga Árabe & 0,032 & 0,024 & 0,021 & 0,022 & 0,017 & 0,026 \\
Tigres Asiáticos & 0,032 & 0,017 & 0,020 & 0,011 & 0,017 & 0,021 \\
África (exclusive Oriente Médio) & 0,031 & 0,030 & 0,034 & 0,048 & 0,042 & 0,048 \\
Caricom & 0,003 & 0,004 & 0,004 & 0,004 & 0,009 & 0,009 \\
\hline
\end{tabular}

FONTE: Resultados da pesquisa.

Em 1996, aproximadamente 51\% dos produtos da indústria paranaense se destinavam à União Européia, evidenciando a alta dependência do estado em relação às condições de demanda dos países pertencentes a este bloco. Contudo, deve-se observar que os valores obtidos apresentaram tendência decrescente, chegando, em 2008, com 31,2\%, evidenciando maior diversificação de destinos.

No que se refere às exportações para o NAFTA, observa-se participação decrescente desse bloco a partir de 2002, ano em que deteve maior participação, 33\%. Em 2008 o bloco era o destino de 11,2\% das exportações industriais do estado, valor semelhante à participação desse mesmo bloco no ano de 1996.

Os blocos Ásia, Liga Árabe e Tigres Asiáticos obtiveram tendências de participações decrescentes ao longo do período. Em média esses blocos foram os destinos de $9 \%, 2 \%$ e 2,5\% do total exportado pelo estado, respectivamente. 
Em contrapartida, alguns blocos obtiveram valores correspondentes a um aumento de importações dos produtos industriais paranaenses. São eles: Mercosul, Aladi e Caricom.

A localização privilegiada, além da competitividade em relação à infraestrutura de transportes são alguns dos aspectos responsáveis pelo aumento da participação do Mercosul no destino das exportações do estado. Em 2002, o bloco deteve $6 \%$ das vendas paranaenses, o valor mais baixo do período em análise. Entretanto, a partir de então, os valores cresceram, apresentando em 2008 a maior participação do bloco (23\%).

Em relação à Associação Latino-Americana de Integração - Aladi (exclusive Mercosul) nota-se um grande crescimento das vendas do estado para este bloco. Inicialmente, em 1996, 3\% das exportações se destinavam aos países pertencentes à associação, já em 2007, esse valor chegou a 15,2\%, com média de detenção de $9 \%$ das exportações paranaenses durante todo o período.

Já a Comunidade e Mercado Comum do Caribe - Caricom obteve participação total média de 0,4\%, com tendência de crescimento.

Segundo Sereia, Nogueira e Camara (2002), as exportações paranaenses são fortemente influenciadas por mudanças nas políticas internas e no contexto econômico mundial. Efeitos dos choques externos são frequentemente transferidos para as regiões exportadoras, manifestando-se no valor das exportações e interferindo no tipo de produto a ser exportado. Conforme os autores, a diversificação da pauta exportadora e a competitividade foram as principais fontes de crescimento das exportações do estado, responsáveis ainda, pela superação das adversidades comerciais externas, resultando em efeitos positivos nas exportações para mercados alternativos.

Os resultados do cálculo do Índice de Comércio Intraindústria estão expressos na Tabela 6, que mostra a heterogeneidade do padrão de comércio entre os grupos de produtos industriais. 
TABELA 6. ÍNDICE DE COMÉRCIO INTRAINDÚSTRIA (GL), 1996-2002

\begin{tabular}{lccccccc}
\hline \multicolumn{1}{c}{ Seções da NCM } & 1996 & 1997 & 1998 & 1999 & 2000 & 2001 & 2002 \\
\hline Seção IV & 0,095 & 0,101 & 0,131 & 0,053 & 0,057 & 0,052 & 0,073 \\
Seção V & 0,222 & 0,178 & 0,045 & 0,065 & 0,039 & 0,069 & 0,246 \\
Seção VI & 0,338 & 0,299 & 0,285 & 0,333 & 0,298 & 0,293 & 0,298 \\
Seção VII & 0,119 & 0,148 & 0,125 & 0,089 & 0,090 & 0,092 & 0,192 \\
Seção VIII & 0,120 & 0,130 & 0,079 & 0,108 & 0,169 & 0,197 & 0,232 \\
Seção IX & 0,248 & 0,235 & 0,207 & 0,075 & 0,097 & 0,068 & 0,036 \\
Seção X & 0,775 & 0,854 & 0,900 & 0,802 & 0,958 & 0,819 & 0,705 \\
Seção XI & 0,734 & 0,741 & 0,887 & 0,888 & 0,818 & 0,780 & 0,624 \\
Seção XII & 0,874 & 0,876 & 0,564 & 0,355 & 0,397 & 0,367 & 0,291 \\
Seção XV & 0,666 & 0,704 & 0,505 & 0,496 & 0,414 & 0,525 & 0,742 \\
Seção XVI & 0,776 & 0,595 & 0,522 & 0,466 & 0,436 & 0,396 & 0,729 \\
Seção XVII & 0,991 & 0,603 & 0,232 & 0,342 & 0,955 & 0,908 & 0,709 \\
Seção XX & 0,299 & 0,437 & 0,650 & 0,698 & 0,743 & 0,815 & 0,653 \\
\hline Indústria & 0,374 & 0,360 & 0,315 & 0,298 & 0,433 & 0,412 & 0,446 \\
\hline
\end{tabular}

FONTE: Resultados da pesquisa.

TABELA 6 (continuação). ÍNDICE DE COMÉRCIO INTRAINDÚSTRIA (GL), 2003-2008

\begin{tabular}{lcccccc}
\hline \multicolumn{1}{c}{ Seções da NCM } & 2003 & 2004 & 2005 & 2006 & 2007 & 2008 \\
\hline Seção IV & 0,072 & 0,079 & 0,106 & 0,097 & 0,102 & 0,103 \\
Seção V & 0,052 & 0,082 & 0,135 & 0,150 & 0,187 & 0,099 \\
Seção VI & 0,377 & 0,308 & 0,398 & 0,391 & 0,323 & 0,228 \\
Seção VII & 0,334 & 0,369 & 0,381 & 0,423 & 0,378 & 0,266 \\
Seção VIII & 0,183 & 0,243 & 0,119 & 0,115 & 0,098 & 0,149 \\
Seção IX & 0,054 & 0,055 & 0,053 & 0,075 & 0,073 & 0,120 \\
Seção X & 0,561 & 0,599 & 0,581 & 0,573 & 0,562 & 0,563 \\
Seção XI & 0,994 & 0,887 & 0,650 & 0,662 & 0,841 & 0,782 \\
Seção XII & 0,253 & 0,388 & 0,505 & 0,603 & 0,542 & 0,844 \\
Seção XV & 0,979 & 0,972 & 0,864 & 0,946 & 0,814 & 0,637 \\
Seção XVI & 0,885 & 0,974 & 0,959 & 0,992 & 0,782 & 0,624 \\
Seção XVII & 0,653 & 0,616 & 0,430 & 0,705 & 0,883 & 0,983 \\
Seção XX & 0,561 & 0,490 & 0,472 & 0,446 & 0,558 & 0,600 \\
\hline Indústria & 0,479 & 0,491 & 0,479 & 0,515 & 0,513 & 0,440 \\
\hline
\end{tabular}

FONTE: Resultados da pesquisa. 
Os grupos de produtos que obtiveram valores próximos de zero em todo o período analisado, e, portanto, são do tipo interindustrial são: Produtos das Indústrias alimentares, bebidas e fumos; Produtos minerais, Produtos das indústrias químicas e conexas; Plásticos, borrachas e suas obras; Peles, couro e peleteria e Madeira, carvão vegetal, cortiça e suas obras (Seções IV, V, VI, VII, VIII e IX respectivamente). O comércio exterior desses produtos é aquele que segue os postulados da teoria Heckscher-Ohlin, que reflete as vantagens comparativas em relação às dotações de fatores de produção do Paraná e seus parceiros comerciais.

Destaca-se que para valores entre zero e a unidade, há efeitos da diferenciação de produtos e da economia de escala e a dotação relativa de fatores é distinta entre os parceiros comerciais. Neste sentido, quanto aos resultados obtidos para os grupos de produtos acima mencionados (valores menores que 0,5 ), a diferença na dotação de fatores entre o Paraná e seus países comerciantes é mais explícita que os efeitos das economias de escala e diferenciação de produtos. De modo paralelo, efeitos de economia de escala e diferenciação de produtos compensam os efeitos das diferenças nas dotações de fatores de produção para valores acima de 0,5 , indicando o comércio do tipo intraindústria.

O grupo de Calçados, chapéus e artefatos (Seção XII) apresentou até 1998 o comércio do tipo intraindústria, a partir do referido ano até 2004 passou a apresentar o comércio do tipo interindústria, e voltou a possuir características comerciais do tipo intraindústria até 2008. Já os produtos dos grupos das Pastas de madeira, papel e suas obras (Seção X) e Materiais têxteis e suas obras (Seção XI) obtiveram valores próximos à unidade, apresentando, assim, o comércio do tipo intraindústria em todo o período em análise. Nota-se, assim, que o referido estado está comercializando esses produtos com países com mesmas características econômicas. Entre as explicações para o fluxo de comércio intraindústria, tem-se a economia de escala e a diferenciação de produtos (Krugman, 1981). Maia (2002) destaca que as barreiras comerciais e as diferenças de gostos, preferências e tecnologias podem também explicar esse padrão de comércio.

Vale ressaltar que alguns grupos de produtos industriais apresentaram padrão de comércio do tipo intraindústria em grande parte do período. Entre 1998 e 2003, e em 2007 e 2008, a seção de Mercadorias e produtos diversos (Seção XX) obteve valores correspondentes ao comércio intraindustrial. O grupo dos Metais comuns e suas obras; Máquinas, aparelhos e materiais elétricos e Materiais de transporte (Seções XV, XVI e XVII respectivamente) resultaram em valores oscilantes, porém na maioria dos anos, obtiveram valores correspondentes ao comércio intraindustrial.

Ao calcular esse índice para a indústria como um todo (considerando a mesma como o somatório dos setores aqui mencionados), observou-se que ela possui 
como característica o comércio interindustrial, em grande parte dos anos. É necessário destacar que os valores para a indústria mostraram tendência crescente, apresentando valores correspondentes ao comércio intraindústria nos anos 2006 e 2007, se aproximando muito de 0,5 entre os anos de 2000 e 2006 e em 2008.

\section{Conclusão}

Neste estudo, analisou-se o comportamento e a estrutura do fluxo comercial externo da indústria paranaense, pautando-se no cálculo dos índices de Vantagem Comparativa Revelada Simétrica, de Contribuição ao Saldo, de Concentração por Produtos e por Blocos e de Comércio Intraindústria.

O Índice de Vantagem Comparativa Revelada Simétrica (VCS) evidenciou que apenas dois grupos de produtos apresentaram vantagem comparativa em todo o período analisado, mostrando que o estado, apesar de apresentar crescentes exportações, possui vantagem comparativa em poucos setores. Destaca-se a forte ligação existente entre os dois setores e o setor primário. Embora o índice apresente valores decrescentes de VCS para os produtos do grupo Alimentares, o oposto acontece no grupo das Madeiras, que obteve valores crescentes durante o período. Além disso, é importante destacar a tendência crescente dos valores obtidos de VCS para o grupo de Materiais de transporte, que começou a apresentar vantagem comparativa a partir de 2000.

Os produtos da indústria paranaense que obtiveram maiores vantagens comparativas simétricas foram também aqueles que apresentaram maior contribuição ao saldo comercial do estado, de acordo com o Índice de Contribuição ao Saldo.

Concernente aos Índices de Concentração por Produtos e por Blocos Econômicos de Destino (ICP e ICD) pôde-se concluir que a economia paranaense é diversificada no que tange à sua pauta exportadora de produtos industriais e concentrada em relação aos destinos de suas vendas. A baixa concentração constatada em relação aos produtos industriais exportados leva a um maior nível de desenvolvimento econômico do estado. Por possuir uma ampla gama de bens com os quais pode comercializar, o estado evita mudanças bruscas em suas receitas de exportações, que porventura possam advir de flutuações de demanda. Em detrimento, verifica-se uma dependência relativa aos blocos importadores de seus produtos industriais. Deve-se, contudo, explicitar a tendência decrescente observada nos valores encontrados para o ICD, o que implica em um esforço de desconcentração dos destinos das exportações industriais do estado.

Considerando toda a indústria, concluiu-se, mediante ao índice de comércio intraindústria que o estado possui estrutura de comércio exterior 
interindustrial, caracterizado pelo fluxo de bens de diferentes setores. Esse tipo de comércio reflete as vantagens comparativas em relação à dotação de fatores de produção entre o estado e países com os quais comercializa. Assim, o Paraná é relativamente eficaz na produção desses bens, pois são intensivos em fatores dos quais é bem dotado. A tendência crescente dos valores obtidos mediante ao índice de comércio intraindústria para a indústria como um todo revela que o estado aumentou as trocas de produtos de um mesmo setor entre seus parceiros comerciais, justificado pela economia de escala, diferenciação de produtos, além das diferenças de gostos, preferências, e tecnologias entre o estado e os países com os quais mantém comércio.

\section{Referências}

BALASSA, B. (1965). "Trade Liberalization and "Revealed" Comparative Advantage". The Manchester School of Economic and Social Studies, vol. 33, p. 99-123.

CUNHA FILHO, M. H.; Carvalho, R. M. (2005). Exportações Brasileiras de Frutas: diversificação ou concentração de produtos e destinos? URL [online]: <http://www.sober.org.br/palestra/2/747.pdf >. Acesso em: dez. de 2009.

FIEP (Federação das Indústrias do Estado do Paraná). (2005). Setores Portadores de Futuro para o Estado do Paraná, horizonte 2015. URL [on-line]: <http://www.fiepr.org.br/observatorios/uploadAddress/ Setores\%20Portadores\%20de\%20Futuro\%20para\%200\%20Paran\%C3\%A1. pdf $>$. Acesso em: maio de 2010.

FEISTEL, P. R. (2006). A natureza do comércio das regiões brasileiras no Mercosul. [Tese de Doutorado]. Programa de Pós-Graduação em Economia da Universidade Federal de Pernambuco (UFPE).

GUIMARÃES, M. C. (2007) O Mercosul e o desempenho do comércio intraindústria do setor brasileiro de papel e celulose. [Mestrado em Economia]. Programa de pós graduação em Economia Aplicada da Universidade Federal de Viçosa (UFV).

GRUBEL, H. G.; LLOYD, P. J. (1975). Intra-industry trade: The theory and measurement of international trade in differential products. New York: Wiley.

HIDALGO, A. B.; Mata, D. F. P. G. da. (2003). "A especialização do nordeste brasileiro e do Estado do Pernambuco no comércio exterior". Texto para Discussão, $\mathrm{n}^{0}$ 465. PIMES/UFPE.

HOLLAND, M.; Xavier, C. L. (2005). "Dinâmica e competitividade setorial das exportações brasileiras: uma análise de painel para o período recente". Economia e Sociedade, vol. 14(1); p. 85-108. 
IPEA (Instituto de Pesquisa Econômica Aplicada). (2011). Dados estatísticos. URL [on-line]: <http://www.ipedata.gov.br>. Acesso em: out. de 2011.

IBGE (Instituto Brasileiro de Geografia e Estatística). (2011). Dados estatísticos. URL [on-line]: <http://www.ibge.gov.br/home/> . Acesso em: out. de 2011.

KRUGMAN, P. R. (1981). "Intraindustry Specialization and the Gains from Trade". Journal of political Economy, vol. 89(5); p. 959-73.

KRUGMAN, P. R.; OBSTFELD, M. (2005). Economia Internacional: Teoria e Política. São Paulo: Makron Books.

LOVE, J. "Trade concentration and export instability". The Journal of Development Studies, v.15, n.3, p. 60-69, 1979.

MAIA, S. F.; MEDEIROS, N. H. (2003). Transformações Recentes na Economia Paranaense: análise de comércio internacional. URL [on-line]: <http:// www.biblioteca.sebrae.com.br/bds/BDS.nsf/706D74B986FF172503256FF 1006580EB/\$File/NToooA6F22.pdf>. Acesso em: ago. de 2009.

MAIA, S. F. (2002). "Efeitos da globalização sobre as vantagens comparativas nas exportações do Paraná: Metodologias comparadas”. In: CONGRESSO BRASILEIRO DE ECONOMIA E SOCIOLOGIA RURAL, 40., 2002, Passo Fundo. Anais. Passo Fundo: SOBER. CD-ROM.

MAIA, S. F.; Trintin, J. G. (2003) "Inserção Mundial da Economia Paranaense: Análise de Comércio Internacional”. In: CONGRESSO BRASILEIRO DE ECONOMIA E SOCIOLOGIA RURAL, 41., 2003, Juiz de Fora. Anais. Juiz de Fora: SOBER. CD-ROM.

MDIC (Ministério do Desenvolvimento, Industria e Comércio). (2009). Indicadores e Estatísticas. URL [on-line]: <http://www.desenvolvimento. gov.br>. Acesso em: jul. de 2009.

NOJIMA, D. (2002). “Crescimento e Reestruturação Industrial no Paraná: 1985/2000”. Revista Paranaense de Desenvolvimento, vol. 103; p. 23-43.

ROCHA, L. E. V.; LEITE, W. T. A. (2007) “Transformações recentes do agronegócio mineiro: Uma análise de indicadores de comércio exterior no período de 1996-2006”. Revista de Economia e Agronegócio, 5 (3): 425-452.

SECEX (Secretaria de Comércio Exterior). (2011) Estatísticas. URL: <http:// www.mdic.gov.br//sitio/interna/index.php?area=5>. Acesso em: 20 out. 2011.

SEREIA, V. J.; Nogueira, J. M.; Camara, M R. G. (2002). “As Exportações Paranaenses e a Competitividade do Complexo Agroindustrial". Revista Paranaense de Desenvolvimento, vol. 103; p. 45-59.

SESSO FILHO, U. A. et al. (2004). “Indústria Automobilística no Paraná: Impactos na produção local e no restante do Brasil”. Revista Paranaense de Desenvolvimento, vol. 106; p. 89-112.

SILVA, J. L. M. da; MONTALVÁN, D. B. V. (2008). “Exportações do Rio Grande do Norte: estrutura, vantagens comparativas e comércio intra-indústria”. Revista de Economia e Sociologia Rural, vol. 46(2); p. 547-568. 
TRINTIN, J. G. (2005). História e desenvolvimento da economia paranaense: da década de trinta a meados dos anos noventa do século XX. URL [online]: <http://www.fee.tche.br/sitefee/download/jornadas/2/e6-04.pdf> Acesso em: mar. de 2009.

XAVIER, C. L. (2001). Padrões de especialização e saldos comerciais no Brasil. URL [on-line]: <http://www.anpec.org.br/encontro2001/ artigos/200103253.pdf >. Acesso em: mar. de 2009.

Recebido em: 17 de janeiro de 2012

Aceito em: 18 de fevereiro de 2013 
